\title{
TENDÊNCIAS EUROPEIAS NA INDEXAÇÃO POR ASSUNTO DE FICÇÃO NARRATIVA
}

\author{
Patrícia de Almeida* \\ Universidad de Coimbra
}

\begin{abstract}
Resumo: A indexação é uma prática antiga e um trabalho complexo, nomeadamente no processo de determinação do assunto. Tratando-se de indexação de Literatura ficcional, a questão torna-se mais difícil, devido à subjetividade e à muldimensionalidade da obra literária. Tradicionalmente, a Literatura não é indexada e os sistemas classificatórios abordam-na pela forma/género literário. Ao longo dos últimos anos, foram surgindo instrumentos de indexação por assunto de ficção narrativa que mostram que esta é possível e necessária. Neste cenário, procura-se saber como se estão a comportar os principais serviços e sistemas de informação europeus, no que toca à indexação de narrativas ficcionais. Para tal, realiza-se um estudo de caso exploratório. Os resultados permitem concluir que a maioria dos países não efetua indexação por assunto de narrativa ficcional e aqueles que efetivamente a fazem localizam-se no norte da Europa. São, portanto, necessários mais estudos e instrumentos para que esta prática se generalize.

Palavras-chave: Indexação; assunto; literatura; ficção; romance; biblioteca nacional; Europa.
\end{abstract}

Título: TENDENCIAS EUROPEAS EN LA INDIZACIÓN POR ASUNTO DE FICCIÓN NARRATIVA.

Resumen: La indización es una práctica antigua y compleja, en particular en el proceso de determinación del asunto. Tratándose de indexación de literatura ficcional, la cuestión se vuelve más difícil, debido a la subjetividad y a la multidimensionalidad de la obra literaria. Tradicionalmente, no es indexada y los sistemas clasificatorios la abordan por la forma. A lo largo de los últimos años, surgen instrumentos de indización por asunto de ficción narrativa que muestran que esta es posible y necesaria. En este escenario, se busca saber cómo se comportan los servicios y sistemas de información europeos con las narrativas ficcionales y se realiza un estudio de caso. Los resultados permiten concluir que la mayoría de los países no efectúa indización por asunto de narrativa ficcional y aquellos que efectivamente la hacen se sitúan en el norte de Europa. Por lo tanto, son necesarios más estudios e instrumentos para que esta práctica se generalice.

Palabras clave: Indización; asunto; literatura; ficción; romance; biblioteca nacional; Europa.

Title: EUROPEAN TRENDS IN INDEXING BY SUBJECT OF NARRATIVE FICTION.

Abstract: Indexing is an old practice and a complex job, particularly in the process of determining the subject (aboutness). Regarding indexing of fictional Literature, the question becomes more difficult, due to the subjectivity and the multidimensionality of the literary work. Traditionally, Literature is not indexed, and classificatory systems address it by form. Over the last few years, instruments of subject indexing of fictional narratives have emerged that show that this is possible and necessary. In this context, we seek to know how the main European services and information systems behave, in terms of the subject indexing of fictional narrative. For this, an exploratory case study is carried out. The results allow us to conclude that most of the countries do not index the fictional narrative by subject and those that actually do it are located in northern Europe. Therefore, we need more studies and instruments for this practice to spread.

Keywords: Indexing; subject; literature; fiction; novel; national library; Europe.

Copyright: (C) 2019 Servicio de Publicaciones de la Universidad de Murcia (Spain). Este es un artículo de acceso abierto distribuido bajo los términos de la licencia Creative Commons Reconocimiento 4.0 Internacional (CC BY 4.0).

\section{INTRODUÇÃO}

Falando-se de organização do conhecimento, reconhece-se que o costume de indexar documentos por assunto tem muitos séculos. Já na Mesopotâmia do século II a.C. se armazenava a informação em tábuas de argila com uma espécie de resumo, o que constituía uma forma de representação condensada do conteúdo informacional dos documentos e permitiria o acesso ao seu assunto (Witty, 1973). Séculos mais tarde, na Europa medieval, é de assinalar o hábito de os monges copistas escreverem na margem dos livros sobre o seu conteúdo, tendo por finalidade a indicação e explicação do assunto em causa.

No entanto, só no século XIX, perante a explosão documental daquele momento da história da humanidade, é que a indexação foi sentida como uma verdadeira necessidade, passando a ser apreciada pelo público dos serviços e

*mebpatricia@gmail.com

Recibido: 24-08-2017; 2 $2^{\mathrm{a}}$ versión: 08-12-2018; aceptado: 17-12-2018.

DE ALMEIDA, P. Tendencias europeas en la indización por asunto de ficción narrativa. Anales de Documentación, 2019, vol. 22, $\mathrm{n}^{\circ}$ 1. Disponible en: http://dx.doi.org/10.6018/analesdoc.22.1.339791. 
sistemas de informação existentes na época. Justifica-se que tal tenha acontecido, uma vez que a indexação é uma operação de representação dos documentos com um objetivo prático que beneficia em muito os utilizadores, a saber, a recuperação da informação (Silva \& Fujita, 2004). Compreende-se, então, que indexar documentos seja tido como um dos trabalhos mais relevantes para a eficácia e para a boa imagem dos serviços e sistemas de informação, já que é fator condicionante nas estratégias e nos resultados das pesquisas dos seus utilizadores (Naves, 2004; Silva \& Fujita, 2004).

Os documentos não indexados são de difícil recuperação nas bases de dados (Saarti, 2002), por vezes só encontrados por um acaso ou serendipidade. Assim, a existência de uma indexação por assunto e a boa qualidade da descrição documental efetuada pelos profissionais da informação condicionam, sem dúvida, o acesso à informação, seja qual for o seu tipo ou suporte. O rigor na indexação evita os ruídos (informação irrelevante) e os silêncios (lapsos de informação pertinente) nas buscas de informação, impedindo que os utilizadores sejam lesados e que se registem possíveis efeitos nocivos na mediação do conhecimento (Redigolo \& Fujita, 2015).

Silva e Fujita (2004) notaram que a literatura sobre indexação por assunto não detalha os seus procedimentos específicos, em particular quando se aborda especificamente a determinação do assunto (aboutness) dos documentos, o que talvez se deva ao facto de este trabalho estar bastante dependente das ações mentais do profissional da informação nos momentos da leitura e da representação dos documentos. Na verdade, a literatura desta área tem-se mostrado dividida até no que toca às fases da indexação. Alguns autores falam em três momentos (por exemplo, Ranganathan, 1967; Rowley, 1982; ISO 5963, 1985; Cleveland \& Cleveland, 1990), genericamente considerados como:

1. Análise do documento para determinação do seu assunto;

2. Extração de conceitos para representar o conteúdo dos documentos em linguagem natural;

3. Tradução de conceitos para termos de linguagem documentária ou de indexação.

Outros autores referem apenas dois momentos (por exemplo, Langridge, 1989; Lancaster, 1993; Anderson \& Pérez-Carballo, 2001; Naves, 2004). Esta divergência explica-se com o entendimento de que os dois primeiros momentos (a ideia do assunto e a sua verbalização) sucedem em simultâneo, sendo que a leitura compreensiva do conteúdo de um determinado documento inclui uma concomitante identificação e seleção de conceitos.

A referida ausência de descrição pormenorizada dos procedimentos específicos da indexação por assunto poderá ainda prender-se com dois fatores: a ausência de normatividade e a presença de subjetividade. Por um lado, a indexação não se rege por leis fixas, mas por princípios e normas, pelo que existe uma saudável flexibilidade e adaptabilidade aos diversos serviços e sistemas de informação. Por outro, e apesar de se apresentar como uma desejável prática rigorosa, a determinação do assunto comporta sempre alguma subjetividade. Lembra Broughton (2004) que decidir sobre o assunto de um livro pode ser muito complicado porque é uma atividade subjetiva, ou seja, o entendimento sobre o que é o assunto pode variar entre os indivíduos e mesmo entre os profissionais da informação. Acresce que não existe nenhuma parte do documento que diga clara e inequivocamente qual o seu assunto.

Esta questão ficará ainda mais complexa se se tratar da indexação por assunto da ficção narrativa (Bell, 1991; Lima, Ribeiro \& Moraes, 2012; Moraes, 2012). É costume considerar a Literatura uma área muito difícil e quase impossível de indexar, pelo menos de forma consistente, exaustiva e específica, à semelhança do que se faz nas áreas científicas e não ficcionais. Ora, tal acontece exatamente devido a especificidades semântico-estruturais próprias da Literatura. Numa perspetiva considerada semântica, importa ter em conta a multidimensionalidade e a subjetividade do próprio texto, uma vez que a obra literária comporta idiossincraticamente abrangência, ambiguidade e livre interpretação (Hypén \& Mäkelä, 2011; Fedeli, 2015). Se se considerar a arquitetura do texto, salienta-se o facto de a narrativa ficcional não encontrar uma estrutura textual definida ou única, podendo este género discursivo discorrer em incontáveis e distintas formas, ao sabor da arte do escritor. Quando comparada com documentos científicos e não ficcionais, a narrativa literária dificilmente encaixa na tradicional estrutura que permite o questionamento e a inferência de conceitos, apresentando uma arquitetura variada e muito própria, em função da tipologia textual do documento em causa. Compreende-se, então, que estas especificidades da ficção narrativa conduzam à inapropriação das tradicionais ferramentas e estratégias metacognitivas de leitura documentária, bem como à alteração dos caminhos metodológicos habituais da indexação, tornando mais árduo o trabalho a efetuar pelo indexador.

Tradicionalmente, os profissionais da informação socorrem-se dos sistemas de classificação bibliográfica e descrevem tecnicamente a ficção narrativa mediante a sua forma/género e não o seu conteúdo, ao contrário do que se passa com as outras áreas do conhecimento. Por exemplo, de acordo com a Classificação Decimal Universal, 82 acomoda a Literatura e as subdivisões auxiliares -1/-9 indicam formas literárias e não assuntos. Talvez se trate de uma estratégia para contornar as dificuldades inerentes às especificidades da Literatura, mas a verdade é que, como confirma Saarti (2002), as classificações deixam intocada a questão da descrição do assunto em ficção, isto é, aquilo 
de que trata ou sobre o que é o documento. Assim, verifica-se que as tabelas classificatórias não constituem um instrumento adequado para a descrição do assunto em Literatura.

Antonio e Moraes (2012) referem que os documentos ficcionais não são indexados por assunto por não existirem instrumentos de análise de assunto adequados às suas especificidades e notam a ausência de procedimentos metodológicos específicos para esta área. A indexação tem sido investigada pela generalidade dos estudiosos da análise do assunto mais no campo documental científico e não no campo ficcional, o que, evidentemente, acarreta consequências a nível das práticas nos serviços e sistemas de informação. De facto, alguma literatura desta área relata problemas nos modelos metodológicos de identificação de conceitos em documentos ficcionais, já que os existentes foram elaborados para documentos não ficcionais (Moraes, 2012; Lima, Ribeiro \& Moraes, 2012; Alves, 2017).

Esta dificuldade advém do facto de a análise das consideradas partes relevantes dos documentos não ser frutífera na determinação do assunto em ficção, já que, na larga maioria dos casos, não se encontram palavras destacadas, listas de conteúdos, introdução e conclusão, ilustrações, esquemas... A leitura de partes, de frases ou de parágrafos iniciais não é suficiente para uma visão do todo e o título não se revela fiável, salientando Broughton (2004) que este pode mesmo ser até enganador. Ora, a impraticabilidade da leitura integral dos documentos por parte dos profissionais de informação é certa, dada a inexistência de tempo para tal.

Muito embora estas condicionantes, vários autores se interessaram por este assunto defendendo a necessidade e a possibilidade de uma indexação por assunto de textos ficcionais, nomeadamente Annelise Mark Pejtersen (1979), Hazel K. Bell (1992), Claire Beghtol (1994), Jarmo Saarti (2002), Kaisa Hypén e Eetu Mäkelä (2011), Alenka Sauperl (2012) ou Larissa Lima, Daiane Ribeiro e João Moraes (2012), entre outros. No limiar do séc. XXI, refere-se que as possibilidades de criação de um sistema de recuperação de informação ficcional aumentaram, muito à custa do desenvolvimento dos ambientes computadorizados (Saarti, 2002). A literatura aqui elencada e as investigações efetuadas até ao momento mostram ser importante e praticável determinar o assunto de documentos ficcionais, caso contrário não serão devidamente exequíveis a pesquisa/recuperação e a prestação de determinados serviços aos utilizadores. Como exemplos concretos e recentes desta vontade e possibilidade, registam-se as propostas desenvolvidas por Fedeli (2015), no âmbito do assunto da narrativa para crianças e jovens, e por Alves (2017), este um modelo de leitura documentária de Literatura do género fábula infantil, com esquemas textuais para fundamentação de estratégias metacognitivas.

A recuperação da informação prende-se com a relevância da informação e esta questão mostra-se pertinente: Não serão as obras de Literatura ficcional importantes para a humanidade? O costume dita que não se indexa qualquer documento, apenas o que poderá ser importante e pesquisado pelo utilizador e as obras de ficção constam, com certeza, deste âmbito. Fedeli (2015) afirma que os utilizadores pesquisam por assunto mesmo as obras ficcionais e que os profissionais da informação, na ausência de uma indexação por assunto, mais não podem fazer do que socorrer-se da sua experiência pessoal. Neste quadro, acredita-se que haverá casos em que as solicitações dos utilizadores dos serviços e sistemas de informação não são atendidas, o que acarreta consequências nefastas não só para a imagem dos serviços e dos seus profissionais como também para os hábitos de leitura dos indivíduos e para a difusão do conhecimento em geral.

Posto isto e mediante os estudos das últimas décadas, que mostram ser possível e necessária a indexação por assunto de obras literárias, surge um ponto de investigação: Como se estão a comportar os serviços e sistemas de informação de referência nos países europeus, no que toca à indexação de obras ficcionais? Tendem a acompanhar a investigação e a implementar práticas de indexação por assunto ou mantêm práticas tradicionais? Para obter respostas, realiza-se um estudo de caráter exploratório em espaço europeu, tendo como objetivos específicos verificar se as bibliotecas nacionais da Europa efetuam indexação por assunto de ficção narrativa e identificar possíveis tendências regionais.

\section{METODOLOGIA}

Para cumprimento destes objetivos, realiza-se um estudo de caso na Europa. Metodologicamente, são consultados os catálogos gerais online das bibliotecas nacionais, assumindo-se o seu papel como referência face a outra tipologia de biblioteca. Seleciona-se uma instituição por país europeu ${ }^{1}$, num máximo de 54.

Em pesquisa avançada por autor e título, procura-se a informação de assunto nos registos catalográficos relativa à obra ficcional narrativa "El ingenioso hidalgo Don Quixote de la Mancha" de Miguel de Cervantes Saavedra (15471616), famoso escritor espanhol. Este romance, clássico da Literatura mundial, teve a sua primeira edição em 1605 (1. ${ }^{\mathrm{a}}$ 
parte) e 1615 (2. ${ }^{\text {a }}$ parte) e é tido como uma das obras mais traduzidas ${ }^{2}$ e mais vendidas ${ }^{3}$ em todo o mundo, tendo sido já considerado o primeiro romance moderno e a melhor obra de ficção ${ }^{4}$. 5 . Trata-se, portanto, de uma amostra por conveniência, que garante a importância social e literária do documento e que procura assegurar uma maior probabilidade de presença no catálogo de todas as bibliotecas.

Para este estudo, são observadas todas as edições do romance de Cervantes desde o ano 2000 (data explícita) e considerada para análise a edição mais recente (total ou parte), independentemente da língua (original ou tradução), uma vez que se pretende aferir das atuais tendências europeias na indexação por assunto de ficção narrativa. Para evitar ruídos de uma possível indexação, não são considerados livros em suporte digital, adaptações a públicos específicos, versões comentadas e ilustradas, edições para estudo ou similares; desta forma, evitam-se termos de assunto como "obra juvenil", "ensino de idiomas", "adaptação didática" ou "documento eletrónico", que nada têm a ver com a obra original.

Dada a multiplicidade de línguas europeias, a pesquisa realiza-se em língua inglesa, sempre que a plataforma o permita, o que acontece na maioria das vezes. No entanto, nem sempre a informação da página surge traduzida na totalidade e é-se forçado a recorrer ao Google tradutor, confirmando-se a tradução em dicionários de língua. Assim, a informação recolhida é copiada na língua original em que se encontra no catálogo e traduzida para Português. Este moroso processo de consulta e tradução de catálogo não é fácil nem linear, tanto mais que, por vezes, existem vários catálogos associados e partilhados, o que poderá ocasionar algum erro e constituir uma limitação deste trabalho. Considera-se, contudo, que uma eventual falha na pesquisa e tradução não inviabiliza a globalidade dos resultados e as conclusões gerais deste estudo de caso.

A pesquisa foi efetuada em agosto de 2018. Os dados recolhidos são transcritos para um quadro e representados em mapa, para posterior análise de resultados e obtenção de conclusões.

\section{APRESENTAÇÃO E DISCUSSÃO DOS RESULTADOS} país.

Após pesquisa em catálogo, a informação recolhida é transcrita e apresentada no quadro I, por ordem alfabética de

\begin{tabular}{|c|c|c|c|}
\hline Biblioteca & Indexação & Assunto & Tradução \\
\hline $\begin{array}{l}\text { Biblioteca Nacional da } \\
\text { Albânia }\end{array}$ & $\begin{array}{l}\text { Fjalët kyçe } \\
\text { (Palavras- } \\
\text { chave) }\end{array}$ & $\begin{array}{l}\text { Letërsia spanjolle } \\
\text { Romane }\end{array}$ & $\begin{array}{l}\text { Literatura espanhola } \\
\text { Romance }\end{array}$ \\
\hline $\begin{array}{l}\text { Biblioteca Nacional da } \\
\text { Alemanha }\end{array}$ & - & - & - \\
\hline $\begin{array}{l}\text { Biblioteca Nacional de } \\
\text { Andorra }\end{array}$ & a) & - & - \\
\hline $\begin{array}{lll}\text { Biblioteca Nacional da } \\
\text { Arménia }\end{array}$ & $\begin{array}{l}\text { funpuiqpip } \\
\text { (Assunto) }\end{array}$ & 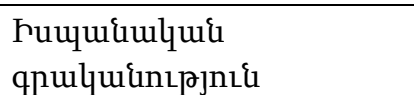 & Literatura espanhola \\
\hline $\begin{array}{l}\text { Biblioteca Nacional da } \\
\text { Áustria }\end{array}$ & $\begin{array}{l}\text { Schlagwörter } \\
\text { (Palavras- } \\
\text { chave) }\end{array}$ & $\begin{array}{l}\text { Roman; Spanien; Cervantes } \\
\text { Saavedra, Miguel de; } \\
\text { Nachdruck }\end{array}$ & $\begin{array}{l}\text { Romance; espanhol; } \\
\text { Cervantes Saavedra, Miguel } \\
\text { de; reimpressão }\end{array}$ \\
\hline $\begin{array}{l}\text { Biblioteca Nacional do } \\
\text { Azerbaijão }\end{array}$ & - & - & - \\
\hline $\begin{array}{l}\text { Biblioteca Nacional da } \\
\text { Bielorrússia }\end{array}$ & - & - & - \\
\hline $\begin{array}{l}\text { Real Biblioteca da } \\
\text { Bélgica }\end{array}$ & - & - & - \\
\hline $\begin{array}{l}\text { Biblioteca Nacional da } \\
\text { Bósnia e Herzegovina }\end{array}$ & - & - & - \\
\hline $\begin{array}{l}\text { Biblioteca Nacional da } \\
\text { Bulgária }\end{array}$ & - & - & - \\
\hline Biblioteca do Chipre & - & - & - \\
\hline $\begin{array}{l}\text { Biblioteca Nacional e } \\
\text { Universitária de Zagreb } \\
\text { (Croácia) }\end{array}$ & - & - & - \\
\hline
\end{tabular}




\begin{tabular}{|c|c|c|c|}
\hline Biblioteca & Indexação & Assunto & Tradução \\
\hline $\begin{array}{l}\text { Biblioteca Nacional da } \\
\text { Dinamarca }\end{array}$ & $\begin{array}{l}\text { Emner } \\
\text { (Assunto) }\end{array}$ & $\begin{array}{l}\text { Don Quixote (Fictitious } \\
\text { character) -- Drama } \\
\text { Knights and knighthood -- } \\
\text { Spain } \\
\text { Panza, Sancho (Fictitious } \\
\text { character) -- Drama } \\
\text { Spain -- Social life and } \\
\text { customs -- 16th century }\end{array}$ & $\begin{array}{l}\text { Dom Quixote (personagem } \\
\text { fictício) - Drama } \\
\text { Cavaleiros e cavalaria - } \\
\text { Espanha } \\
\text { Pança, Sancho (personagem } \\
\text { fictício) - Drama } \\
\text { Espanha - Vida social e } \\
\text { costumes - século XVI }\end{array}$ \\
\hline $\begin{array}{l}\text { Biblioteca Nacional da } \\
\text { Escócia }\end{array}$ & $\begin{array}{l}\text { Subjects } \\
\text { (Assuntos) }\end{array}$ & $\begin{array}{l}\text { Don Quixote (Fictitious } \\
\text { character)--Fiction. } \\
\text { Knights and knighthood-- } \\
\text { Spain--Fiction. } \\
\text { Spain--Social life and } \\
\text { customs--Fiction. }\end{array}$ & $\begin{array}{l}\text { Dom Quixote (personagem } \\
\text { fictício) - ficção. } \\
\text { Cavaleiros e cavaleiros - } \\
\text { Espanha - Ficção. } \\
\text { Espanha - Vida social e } \\
\text { costumes - Ficção. }\end{array}$ \\
\hline $\begin{array}{l}\text { Biblioteca Nacional da } \\
\text { Eslováquia }\end{array}$ & a) & - & - \\
\hline $\begin{array}{lr}\text { Biblioteca Nacional } & \mathrm{e} \\
\text { Universitária } & \mathrm{da} \\
\text { Eslovénia } & \\
\end{array}$ & a) & - & - \\
\hline $\begin{array}{l}\text { Biblioteca Nacional de } \\
\text { Espanha }\end{array}$ & - & - & - \\
\hline $\begin{array}{l}\text { Biblioteca Nacional da } \\
\text { Estónia }\end{array}$ & - & - & - \\
\hline $\begin{array}{l}\text { Biblioteca Nacional da } \\
\text { Finlândia }\end{array}$ & $\begin{array}{l}\text { Aiheet } \\
\text { (Assunto) }\end{array}$ & $\begin{array}{l}\text { venäjänkielinen } \\
\text { käännöskirjallisuus } \\
\text { espanjankielinen } \\
\text { kirjallisuus } \rightarrow \text { romaanit }\end{array}$ & $\begin{array}{l}\text { Tradução em russo-língua } \rightarrow \\
\text { literatura espanhola } \rightarrow \\
\text { romances }\end{array}$ \\
\hline $\begin{array}{ll}\text { Biblioteca Nacional de } \\
\text { França }\end{array}$ & - & - & - \\
\hline $\begin{array}{l}\text { Biblioteca Nacional e } \\
\text { Parlamentar da Geórgia }\end{array}$ & 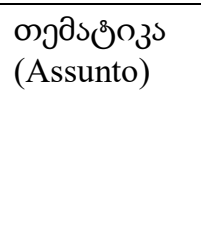 & 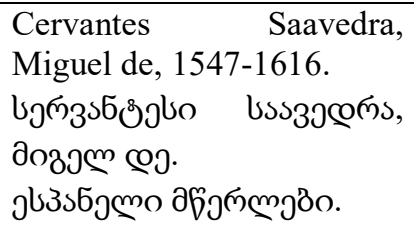 & $\begin{array}{l}\text { Cervantes Saavedra, Miguel } \\
\text { de, } 1547-1616 . \\
\text { Cervantes, Miguel de. } \\
\text { Escritores espanhóis }\end{array}$ \\
\hline $\begin{array}{l}\text { Biblioteca Nacional da } \\
\text { Grécia }\end{array}$ & - & - & - \\
\hline $\begin{array}{l}\text { Biblioteca Nacional } \\
\text { Széchényi (Hungria) }\end{array}$ & $\begin{array}{l}\text { Tárgyszavak } \\
\text { (palavras- } \\
\text { chave) }\end{array}$ & $\begin{array}{l}\text { spanyol irodalom } \\
\text { regény }\end{array}$ & $\begin{array}{l}\text { literature espanhola } \\
\text { romance }\end{array}$ \\
\hline $\begin{array}{l}\text { Biblioteca } \\
\text { (Inglaterra) }\end{array}$ & $\begin{array}{l}\text { Subjects } \\
\text { (Assuntos) }\end{array}$ & $\begin{array}{l}\text { Don Quixote (Fictitious } \\
\text { character) -- Fiction; Spain } \\
\text {-- Social life and customs -- } \\
\text { 16th century -- Fiction; } \\
\text { Dewey: } 863\end{array}$ & $\begin{array}{l}\text { Dom Quixote (personagem } \\
\text { fictício) - ficção; Espanha - } \\
\text { Vida social e costumes - } \\
\text { século XVI - Ficção; } \\
\text { Dewey: } 863\end{array}$ \\
\hline $\begin{array}{l}\text { Biblioteca Nacional da } \\
\text { Irlanda }\end{array}$ & - & - & - \\
\hline $\begin{array}{l}\text { Biblioteca Linen Hall } \\
\text { (Irlanda do Norte) }\end{array}$ & a) & - & - \\
\hline $\begin{array}{l}\text { Biblioteca nacional e } \\
\text { Universitária da Islândia }\end{array}$ & $\begin{array}{l}\text { Efnisorð } \\
\text { (Assunto) }\end{array}$ & $\begin{array}{l}\text { Skáldsögur; } \\
\text { bókmenntir }\end{array}$ & $\begin{array}{l}\text { Romances; } \\
\text { espanhola }\end{array}$ \\
\hline $\begin{array}{l}\text { Biblioteca Nacional de } \\
\text { Roma (Itália) }\end{array}$ & - & - & - \\
\hline $\begin{array}{l}\text { Biblioteca Nacional do } \\
\text { Kosovo }\end{array}$ & $\begin{array}{l}\begin{array}{l}\text { Subject } \\
\text { (Assunto) }\end{array} \\
\end{array}$ & $\begin{array}{l}\text { Letërsia spanjolle } \\
\text { Përkthime në shqip } \\
\end{array}$ & $\begin{array}{l}\text { Literatura Espanhola } \\
\text { Tradução para o albanês }\end{array}$ \\
\hline
\end{tabular}




\begin{tabular}{|c|c|c|c|}
\hline Biblioteca & Indexação & Assunto & Tradução \\
\hline & & Romane spanjolle & Romance espanhol \\
\hline $\begin{array}{l}\text { Biblioteca Nacional da } \\
\text { Letónia }\end{array}$ & $\begin{array}{l}\text { Priekšmets } \\
\text { (Assuntos) }\end{array}$ & Spāṇu romāni & Romances espanhóis \\
\hline $\begin{array}{l}\text { Biblioteca Nacional do } \\
\text { Liechtenstein }\end{array}$ & - & - & - \\
\hline $\begin{array}{l}\text { Biblioteca Nacional } \\
\text { Martynas Mazvydas da } \\
\text { Lituânia }\end{array}$ & $\begin{array}{l}\text { Tema } \\
\text { (Assunto) }\end{array}$ & Romanai, ispanų & Romance, espanhol \\
\hline $\begin{array}{l}\text { National Library of } \\
\text { Luxembourg }\end{array}$ & - & - & - \\
\hline $\begin{array}{l}\text { Biblioteca Nacional e } \\
\text { Universitária St. Kliment } \\
\text { Ohridski (Macedónia) }\end{array}$ & - & - & - \\
\hline $\begin{array}{l}\text { Biblioteca Nacional de } \\
\text { Malta }\end{array}$ & - & - & - \\
\hline Mediateca do Mônaco & $\begin{array}{l}\text { Sujet } \\
\text { (Assunto) }\end{array}$ & Classification Romans & Classificação Romance \\
\hline $\begin{array}{l}\text { Biblioteca Nacional } \\
\text { Central do Montenegro }\end{array}$ & - & - & - \\
\hline $\begin{array}{l}\text { Biblioteca Nacional da } \\
\text { Noruega }\end{array}$ & - & - & - \\
\hline $\begin{array}{l}\text { Biblioteca Nacional do } \\
\text { País de Gales }\end{array}$ & $\begin{array}{l}\text { Pynciau } \\
\text { (Assuntos) }\end{array}$ & $\begin{array}{l}\text { Don Quixote (Fictitious } \\
\text { character) -- Fiction; } \\
\text { Knights and knighthood -- } \\
\text { Spain -- Fiction; Spain -- } \\
\text { Social life and customs - } \\
\text { Fiction }\end{array}$ & $\begin{array}{l}\text { Don Quixote (personagem } \\
\text { fictício) - ficção; Cavaleiros } \\
\text { e cavaleiros - Espanha - } \\
\text { Ficção; Espanha - Vida } \\
\text { social e costumes - Ficção }\end{array}$ \\
\hline $\begin{array}{l}\text { Biblioteca Nacional dos } \\
\text { Países Baixos }\end{array}$ & $\begin{array}{l}\text { Subject } \\
\text { heading } \\
\text { Depot } \\
\text { (cabeçalho de } \\
\text { assunto) }\end{array}$ & $\begin{array}{l}\text { romans en novellen; } \\
\text { vertaald }\end{array}$ & $\begin{array}{l}\text { romances em romances; } \\
\text { traduzido }\end{array}$ \\
\hline $\begin{array}{l}\text { Biblioteca Nacional da } \\
\text { Polónia }\end{array}$ & $\begin{array}{l}\text { Temat } \\
\text { (Assunto) }\end{array}$ & $\begin{array}{l}\text { Cervantes } \begin{array}{l}\text { Saavedra, } \\
\text { Miguel de (1547-1616). }\end{array} \\
\text { Don Quijote de la Mancha } \\
\text { Don Kichot (postać } \\
\text { fikcyjna) } \\
\text { Sancho Pansa (postać } \\
\text { fikcyjna) } \\
\text { Etos rycerski } \\
\text { Rycerze } \\
\text { Wyobraźnia } \\
\text { Hiszpania } \\
\text { La Mancha (Hiszpania) }\end{array}$ & $\begin{array}{l}\text { Cervantes Saavedra, Miguel } \\
\text { de (1547-1616). Dom } \\
\text { Quijote de la Mancha } \\
\text { Dom Quixote (personagem } \\
\text { fictício) } \\
\text { Sancho Pança (personagem } \\
\text { fictício) } \\
\text { Etos do Cavaleiro } \\
\text { Cavaleiros } \\
\text { Imaginação } \\
\text { Espanha } \\
\text { La Mancha (Espanha) }\end{array}$ \\
\hline $\begin{array}{l}\text { Biblioteca Nacional de } \\
\text { Portugal }\end{array}$ & - & - & - \\
\hline $\begin{array}{ll}\text { Biblioteca Nacional } & \text { da } \\
\text { República } & \\
\text { Cazaquistão } & \text { do }\end{array}$ & b) & - & - \\
\hline $\begin{array}{l}\text { Biblioteca Nacional da } \\
\text { República Checa }\end{array}$ & - & - & - \\
\hline $\begin{array}{l}\text { Biblioteca Nacional da } \\
\text { República da Moldávia }\end{array}$ & - & - & - \\
\hline $\begin{array}{l}\text { Biblioteca Nacional da } \\
\text { Roménia }\end{array}$ & - & - & - \\
\hline
\end{tabular}




\begin{tabular}{|c|c|c|c|}
\hline Biblioteca & Indexação & Assunto & Tradução \\
\hline $\begin{array}{l}\text { Biblioteca Nacional da } \\
\text { Rússia }\end{array}$ & - & - & - \\
\hline $\begin{array}{l}\text { Biblioteca Nacional de } \\
\text { San Marino }\end{array}$ & - & - & - \\
\hline $\begin{array}{l}\text { Biblioteca Nacional da } \\
\text { Sérvia }\end{array}$ & - & - & - \\
\hline $\begin{array}{l}\text { Biblioteca Nacional da } \\
\text { Suécia }\end{array}$ & $\begin{array}{l}\text { Ämnesord } \\
\text { (Assunto) }\end{array}$ & $\begin{array}{l}\text { Knights and knighthood -- } \\
\text { Fiction. (LCSH) } \\
\text { Spain -- Social life and } \\
\text { customs -- 16th century -- } \\
\text { Fiction. (LCSH) }\end{array}$ & $\begin{array}{l}\text { Cavaleiros e cavaleiros - } \\
\text { Ficção. (LCSH) } \\
\text { Espanha - Vida social e } \\
\text { costumes - século XVI - } \\
\text { Ficção. (LCSH) }\end{array}$ \\
\hline $\begin{array}{l}\text { Biblioteca Nacional da } \\
\text { Suiça }\end{array}$ & a) & - & \\
\hline $\begin{array}{l}\text { Biblioteca Nacional da } \\
\text { Turquia }\end{array}$ & $\begin{array}{l}\text { Konu Ek } \\
\text { Girişi (Yerel, } \\
\text { Güncel) } \\
\text { (cabeçalho de } \\
\text { assunto } \\
\text { (local, } \\
\text { atualidade) }\end{array}$ & İspanyol romanı & romance espanhol \\
\hline $\begin{array}{l}\text { Biblioteca Nacional } \\
\text { Vernadsky da Ucrânia }\end{array}$ & $\begin{array}{l}\text { Тематичні } \\
\text { рубрики } \\
\text { (Secções } \\
\text { temáticas) } \\
\end{array}$ & література & Ficção (obras) \\
\hline Biblioteca do Vaticano & b) & - & \\
\hline
\end{tabular}

Quadro I. Resultados da pesquisa nos catálogos das bibliotecas europeias.

De um universo de 54 possíveis países na Europa ${ }^{6}$, conseguiu-se obter dados relativos a 47 (87\%), número que servirá de referência total percentual. Ficam excluídos:

- Andorra, Eslováquia, Eslovénia, Irlanda do Norte e Suíça - por não apresentarem explicitamente uma edição de acordo com os critérios de seleção deste estudo, a saber obra original ou traduzida posterior ao ano 2000;

- República do Cazaquistão e Vaticano - por não se encontrar no catálogo a obra em análise.

Neste quadro e de uma forma geral, pode verificar-se que os catálogos das bibliotecas de 20 países apresentam marcas de indexação, o que corresponde a $42,5 \%$ (percentagem arredondada às décimas). Estes países situam-se essencialmente na região da Europa Britânica, Nórdica e de Leste (Figura 1). De acordo com a tradução efetuada, a indexação revela-se, de forma explícita, maioritariamente em "assunto(s)" (catorze vezes), ocorrendo também como "palavras-chave" (três vezes), "cabeçalho de assunto" (duas vezes) e "secções temáticas" (uma vez). Em acordo com a tradição da área da biblioteconomia, uma maioria simples dos catálogos das bibliotecas nacionais não apresenta qualquer marca de indexação, a saber, 27 países, essencialmente da Europa Ibérica, Central e Balcãs, o que corresponde a 57,5\% (percentagem arredondada às décimas).

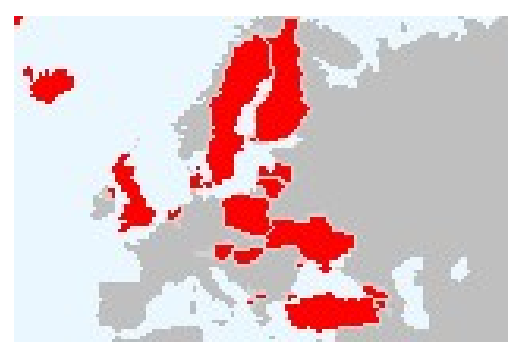

Figura 1. Países cujo catálogo da biblioteca apresenta indexação ${ }^{7}$.

Da consulta aos registos desde o ano 2000, em Chipre e em Estónia, verifica-se que apenas a última edição do romance de Cervantes (a considerada neste estudo, de 2007 e de 2011, respetivamente) não apresenta descritores de assunto. Isto poderá significar um lapso ou um atraso no trabalho de indexação ou mesmo a descontinuidade desta prática, por um qualquer motivo a determinar. Só um contacto direto com os profissionais de indexação das bibliotecas em causa o poderia esclarecer. No entanto, uma eventual alteração destes dados permitiria a aproximação 
entre as percentagens aferidas, com maior equilíbrio entre catálogos com e sem marcas de indexação e, consequentemente, um equilíbrio entre possíveis tendências.

Num olhar mais atento aos descritores de assunto verificados nos catálogos, constata-se que estes dizem respeito a diferentes aspetos do romance de Cervantes, a saber:

- forma/género literário e classificação - "literatura espanhola", "romance espanhol", "ficção", "romance” e "Dewey 863";

- autoria - "escritores espanhóis" e "Cervantes Saavedra, Miguel de";

- edição - "reimpressão", "traduzido", "tradução para albanês” e "tradução em russo-língua";

- $\quad$ assunto - "Dom Quixote (personagem fictícia)", "Sancho Pança (personagem fíctícia), "Cavaleiros e cavalariaEspanha", "Espanha-Vida social e costumes-Séc.XVI", "etos do cavaleiro", "cavaleiros", "imaginação", "Espanha" e "La Mancha (Espanha)".

Uma vez que a maioria dos descritores se refere a aspetos da obra (forma/género, classificação, edição, autor) e não ao seu assunto, isto é, aquilo de que o livro efetivamente trata ou é sobre (à semelhança do que acontece em textos não ficcionais), poder-se-á considerar que os números aqui anteriormente apresentados são falaciosos e que, portanto, a descrição do assunto em ficção ainda é terreno pouco explorado na Europa. Nos catálogos das bibliotecas, existem campos próprios para este tipo de informações, por vezes fornecidas de forma redundante ou pouco útil (ruído). A título de exemplo, veja-se que o autor/escritor tem já um campo específico e que os sistemas classificatórios CDD ou CDU já informam de que se trata de um romance da literatura espanhola.

Assim, se se tiver em conta apenas a informação relativa ao assunto efetivo do romance, a percentagem de catálogos com real indexação por assunto desce consideravelmente para $12,8 \%$ (arredondado às décimas), correspondente a apenas 6 países, localizados no norte da Europa (Figura 2).

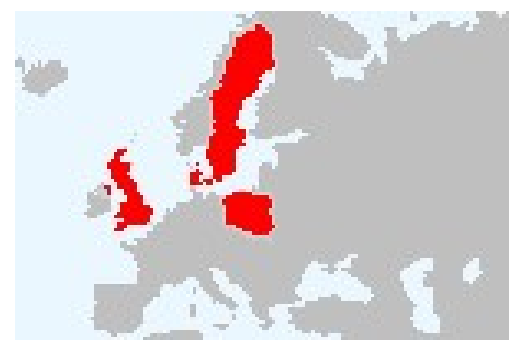

Figura 2. Países cujo catálogo da biblioteca apresenta efetiva indexação por assunto ${ }^{7}$.

Tal poderá ocorrer devido ao peso conferido pela tradição ou devido à ausência de instrumentos adequados para a indexação por assunto de ficção, como se refere na generalidade literatura da área. Muito embora, podendo não ser perfeitos ou exaustivos, verifica-se que estes instrumentos existem e que são até explicitados, como se verifica no catálogo da biblioteca nacional da Suécia que refere, em sigla, a Library of Congress Subject Headings. Aliás, os descritores de assunto de Suécia, Dinamarca, Escócia, País de Gales e Inglaterra são demasiado semelhantes para não se considerar que sofreram a mesma influência do modelo norte-americano por cabeçalhos de assunto. Neste caso, confirma-se que o velho continente parece manter a tradição de não indexar por assunto a Literatura ou que segue os passos do novo mundo.

Nos resultados obtidos, destaca-se a Polónia, o país cujo resultado da pesquisa no catálogo se diferencia pelo número de descritores encontrados (oito), pela distinção semântica (as diferenças face às restantes propostas também levam a crer que este país não segue o modelo norte-americano) e pela abrangência (encontram-se descritores relativos a distintas categorias, tais como autor, personagens principais, localização espacial e microtemas bastante específicos). Desta forma, a indexação efetuada pela Biblioteca Nacional da Polónia parece ser um interessante caso de estudo para futuras investigações nesta área, vindo confirmar que o assunto pode efetivamente variar entre os profissionais da informação, mesmo existindo um modelo já seguido por outras bibliotecas. De momento, acredita-se que esta seja uma boa tentativa de alcançar a multidimensionalidade do texto ficcional, sem dúvida a mais exaustiva na descrição do assunto da obra literária em causa nesta investigação.

\section{CONCLUSÕES}

Nos resultados deste estudo de caso exploratório realizado em território europeu, constata-se que, tratando-se de ficção narrativa, quase metade das bibliotecas nacionais da Europa tende a preencher o espaço do catálogo reservado à indexação. No entanto, apenas uma percentagem diminuta o faz centrando-se efetivamente no assunto da obra literária 
e isto acontece quase sempre sob influência do modelo norte-americano. Parece, então, existir uma vontade de disponibilizar o assunto de um documento ficcional aos utilizadores, todavia ainda impera o peso da tradição na indexação, que criou o hábito de se considerar a obra literária como assunto e não o assunto da obra literária. Defendese que este procedimento deverá ser alterado, pois não se trata de preencher um campo de indexação apenas porque este existe, mas de fornecer descritores verdadeiramente úteis sobre a obra literária, que permitam o seu conhecimento e a recuperação da informação pelos utilizadores.

No que toca às tendências regionais, verifica-se que existem divisões na Europa, sendo as regiões ibérica, central e balcãs menos propensas a uma possível indexação de ficção e sendo o norte da Europa a área geográfica tendente a proporcionar uma efetiva indexação por assunto de obras literárias. Na globalidade, afere-se que a maior parte da velha Europa se encontra imobilizada pelo peso da tradição, que dita a não indexação de Literatura ou a sua consideração pela forma/género, e que uma outra parte está a ser influenciada por um instrumento de indexação externo a si.

Conclui-se, portanto, que os principais serviços e sistemas de informação dos países europeus tendem a manter a tradição de não indexar os documentos ficcionais ou de o fazer tendo em consideração o documento como objeto e a sua forma/género literário. Como apontado pela literatura da área da biblioteconomia, a questão do assunto em obras literárias continua aqui pouco explorada. Acredita-se que esta situação condicione as pesquisas nos catálogos europeus e que tenha impacto na recuperação da informação, na imagem dos serviços prestados pelas bibliotecas, na igualdade de acesso à informação. Face à grande ausência de resultados efetivos de indexação por assunto de ficção narrativa, depreende-se que são verdadeiramente necessários mais estudos e instrumentos adequados às especificidades da Literatura, para que esta prática se estabeleça de uma forma generalizada nas bibliotecas europeias.

Esta investigação encontra limitações no período temporal, nas dificuldades de pesquisa e tradução e no número de obras literárias em análise, pelo que se recomendam os desejáveis e necessários estudos na área da indexação de ficção, a fim de completar ou complementar o trabalho efetuado.

\section{NOTAS}

\footnotetext{
${ }^{1}$ No caso de um país possuir mais do que uma biblioteca nacional, como é o caso de Hungria e de Itália, é considerada a biblioteca localizada na capital desse país, por se considerar aqui um maior peso referencial. O Principado do Mônaco não tem uma designada biblioteca nacional, sendo que as obras de ficção para adultos se encontram englobadas na mediateca. Também a Irlanda do Norte não designa nenhuma das suas bibliotecas com nacional, sendo aqui considerada a mais antiga biblioteca da capital do país.

${ }^{2} \mathrm{Ver}<\mathrm{http}: / /$ www.revistaestante.fnac.pt/os-livros-mais-traduzidos-de-sempre/>.

${ }^{3} \mathrm{Ver}<\mathrm{https}: / /$ top10mais.org/top-10-livros-mais-vendidos-de-todos-os-tempos/>.

${ }^{4} \mathrm{Ver}<\mathrm{https}: / /$ www.britannica.com/biography/Miguel-de-Cervantes\#ref215817>.

${ }^{5}$ Ver $<$ https://www.theguardian.com/world/2002/may/08/humanities.books $>$.

${ }^{6}$ Países transcontinentais, como Rússia, Cazaquistão, Azerbaijão, Geórgia, Turquia, Arménia e Chipre, foram considerados neste estudo, de forma a obter uma visão mais alargada das tendências europeias.

${ }^{7}$ No sistema informático de construção de mapas, não foi possível diferenciar a Irlanda do Norte por ser uma nação constituinte do Reino Unido.
}

\section{REFERÊNCIAS BIBLIOGRÁFICAS}

ALVES, R. Modelo de leitura documentária para indexação de literatura infantil do gênero fábula: esquemas textuais para fundamentação de estratégias metacognitivas. In FUJITA, M., NEVES, D., \& DAL'EVEDORE, P. (Org.). Leitura documentária: estudos avançados para a indexação. Marília: Oficina Universitária/ São Paulo: Cultura Acadêmica, 2017.

ANDERSON, J., \& PÉREZ-CARBALLO, J. The nature of indexing: how humans and machines analyse messages and texts for retrieval. Part I: Research, and the nature of human indexing. Information Processing and Management, 2001, vol. 37, n. 2, p. 231-254.

ANTONIO, D., \& MORAES, J. Aboutness in Fiction: Methodological Perspectives for Knowledge Organization. In GUIMARÃES, J., \& DODEBEI, V. (Ed.). Desafios e perspectivas científicas para a organização e representação do conhecimento na atualidade. Marília: ISKO Brasil-FUNDEPE, 2012.

BEGHTOL, C. The Classification of Fiction: The Development of a System Based on Theoretical Principles. Metuchen, NJ: Scarecrow Press, 1994.

BELL, H. Indexing fiction: a story of complexity. The Indexer, 1991, vol. 17, n. 4, p. 251-256.

BELL, H. Should fiction be indexed? The indexability of text. The Indexer, 1992, vol. 18, n. 2, p. 83-86.

BROUGHTON, V. Essential classification. London: Facet Publishing, 2004. 
CLEVELAND, B., \& CLEVELAND, A. Introduction to indexing and abstracting. Englewood: Libraries Unlimited, 1990.

FEDELI, S. La soggettazione della narrativa per bambini e ragazzi. Italian Journal of Library, Archives and Information Science, 2015, vol. 6, n. 3, p. 101-120.

HYPÉN, K., \& MÄKELÄ, E. An ideal model for an information system for fiction and its application: Kirjasampo and Semantic Web. Library Review, 2011, vol. 60, n. 4, p. 279-292.

ISO 5963. Documentation - Méthodes pour l'analyse des documents, la détermination de leur contenu et la sélection des termes d'indexation. In Documentation et information: recueil de normes. Genève: ISO, 1985.

LANCASTER, F. Indexação e resumos: teoria e prática. Brasília: Briquet de Lemos, 1993.

LANGRIDGE, D. Subjectc analysis: principles and procedures. London: Bowker-Saur, 1989.

LIMA, L., RIBEIRO, D., \& MORAES, J. Análise documental de textos narrativos de ficção: uma proposta metodológica com vistas à identificação do tema. Múltiplos Olhares em Ciência da Informação, 2012, vol. 2, n. 2, p. 1-13.

MORAES, J. Aboutness in Fiction: Methodological Perspectives for Knowledge Organization. In NEELAMEGHAN, A., \& RAGHAVAN, K. (Ed.). Advances in Knowledge Organization - Proceedings of the Twelfth International ISKO Conference. Mysore: Ergon Verlag, 2012.

NAVES, M. Curso de Indexação. Princípios e técnicas de indexação, com vistas à recuperação da informação. Belo Horizonte: UFMG Biblioteca Universitária, 2004.

PEJTERSEN, A. The meaning of'about'in fiction indexing and retrieval. Aslib Proceedings, 1979, vol. 31, n. 5, p. 251-257.

RANGANATHAN, S. Prolegomena to library classification. Bombay: Asia Publishing House, 1967.

REDIGOLO, F., \& FUJITA, M. A leitura profissional do catalogador e seu papel como mediadora da informação. Informação \& Informação, 2015, vol. 20, n. 3, p. 356-376.

ROWLEY, J. Abstracting and indexing. London: Clive Bingley, 1982.

SAARTI, J. Aspects and methods of fictional literature knowledge organization. Consiglio Nazionale delle Ricerche, 2002 [online]. Disponível em: $<$ http://citeseerx.ist.psu.edu/viewdoc/download?doi=10.1.1.103.1036\&rep=rep1\&type=pdf $\quad$ [Acesso em 10 janeiro 2018]

ŠAUPERL, A. Pinning down a novel: characteristics of literary works as perceived by readers, Library Review, 2012 , vol. 61, n. 4 p. 286-303.

SILVA, M., \& FUJITA, M. A prática de indexação: análise da evolução de tendências teóricas e metodológicas. Transinformação, 2004, vol. 16, n. 2, p. 133-161.

WITTY, F. The beginnings of indexing and abstracting: some notes towards a history of indexing and abstracting in antiquity and the middle ages. The Indexer, 1973, vol. 8, n. 4, p. 193-198. 